\title{
Developing a School Based Model for Optimising the Professional Development of Canadian Primary School Teachers
}

\author{
Jonathan Pitt \\ School of Education, Nipissing University \\ North Bay, Ontario, Canada \\ E-mail: jonathap@nipissingu.ca
Hettie van der Merwe (Corresponding author)
University of South Africa, UNISA
Pretoria, South Africa
E-mail: vdmerhm@unisa.ac.za

Accepted: June 6, 2012 Published: July 09, 2012

Doi:10.5296/ijld.v2i4.1923ＵRL: http://dx.doi.org/10.5296/ijld.v2i4.1923

\begin{abstract}
The purpose of this study was to develop a school based model for optimizing the professional development of Canadian primary school teachers. This study focused on the role of the school principal in teacher development and improving learner achievement data. This study utilised a literature review covering a comprehensive review of existing models of teacher development, the school as a professional learning community and the role of the school principal. The empirical investigation was based on a mixed methods approach using a quantitative questionnaire with a sample of 145 out of a possible 200 (representing a $73 \%$ return rate) and twenty (10 school principals \& 10 teachers) qualitative semi-structured in-depth individual interviews to gather data from both a teacher group and a school management group from a teacher education faculty at a local university and a selected English Public school district in Canada in the province of Ontario.
\end{abstract}

Keywords: Teacher development, school principal, professional learning community, school climate, school culture, staffroom, teacher. 


\section{Introduction}

The central research question of this study involved developing a school based model for optimising the professional development of Canadian primary school teachers with specific attention to the role of the school principal in this process. The investigation on the role of the school principal in teacher development was planned to include a contextual investigation in order to achieve deeper knowledge on the influence of the school principal on teacher development using an investigative approach to establish guidelines for optimising the professional development of teachers. A series of conclusions and recommendations are presented in this article based on the analysis of a review of literature and of the investigation connecting this examination to the creation of a teacher development model. The research findings are based on data collected through a mixed methods research approach employing individual interviews and a questionnaire.

Matters of professional teacher development such as the main elements of successfully enhancing learner achievement by improving instructional techniques of teachers have been previously identified (DuFour \& Eaker, 1998, Fullan, 2001, Fullan, Hill, \& Crevola, 2006, Speck, 1998). Against this backdrop, the development for an effective approach to teacher growth with individualised development options for teachers was examined, integrating the perspectives of both teachers and school principals.

\section{Literature Review}

The chief focus of the literature review was to highlight the components of professional teacher development. A review of the literature on the approaches to teacher development, the main elements of professional learning communities and the role of the school principal in teacher development was first completed to provide the background for this study with regard to the school principal. The starting point for understanding teacher development lies in the career life cycle of the teacher as it is linked to the knowledge and skills of instructional techniques retained by the teacher (Barth, 1990; Darling-Hammond, 1993; Day, 1999; Hargreaves, 1994; Lacey, 1977; Leithwood, 1990). The key factor in teacher development connects to the operational knowledge of the school principal given the contemporary challenges facing teachers (Speck, 1998; Thies-Sprinthall, 1984; Thies-Sprinthall \& Reiman, 1994). In the current mainstream school system, teachers require different instructional skills than those employed in past decades. A well-designed, practical and continuous method to teacher development is necessary for improving learner achievement. The salient themes of teacher development, such as professional learning communities, teachers' working conditions, professional workplace relationships, and the role of the school principal, are centered on sustained career-long staff development (Day, 1999; Leithwood, 1990).

The traditional methods of developing teachers have not resulted in lasting teacher development due to a lack of support and maintenance between curriculum theory-based workshops and the practical application of curriculum theory in the mainstream classroom. The established teacher development approaches tend to cope with improving the instructional techniques of teachers in a one-size-fits-all or cookie cutter practise. A conventional system of 
teacher development such as completing additional degrees (Frost, Durrant, Head \& Holden, 2000; Meier, 1995) attending curriculum theory-based workshops (Delong, Black, and Wideman, 2005; Hannay, Wideman and Seller, 2006) and the teacher performance appraisal (Blankstein, 2004; Fullan, 2001; Parkay, Stanford, Vaillancourt \& Stephens, 2005) has called for improved methods of teacher development that integrates training at the school level to meet the demands of the contemporary classroom. Methods of teacher development such as action research (Calhoun, 1994; Darling-Hammond \& Bransford, 2005; Delong, Black \& Wideman, 2005) involving the interaction structure of professional learning community meetings (DuFour \& Eaker, 1998; Hannay, Wideman \& Seller, 2006; O’Day, 2002) can be supported and maintained through approaches such as peer coaching (Blasé \& Blasé, 1998; Joyce \& Showers, 1995) and informal discussions on improving teacher performance (Pitt, 2011; Pitt \& Kirkwood, 2009).

An examination of the literature on the school based professional learning communities has yielded positive results. By combining the individual development of teachers with improving learner achievement the discourse concerning what and how teachers develop becomes more refined. Within a school based model of teacher development, the approaches used by school principals to enhance the performance of teachers is equally dependent on the working conditions of teachers (Blankstein, 2004; DuFour, 2007; DuFour \& Eaker, 1998). Ministries of Education require that teachers and school principals preform specific duties with attention to tasks as required by the education law of compulsary schooling. The implementation of Ministry of Education policies by school principals across the world (McNergney \& Carrier, 1981; Ontario Ministry of Education, 2006; Speck, 1998) supports the achievement of learners, thus supporting teacher development by bringing greater focus to the relationship between classroom instruction and learner outcomes (Speck, 1998: 39 \& 154).

The review of literature also contextualised the school principal as the prime factor in teacher development within the school. School principals can facilitate collaboration and collegiality (DuFour \& Eaker, 1998; Hargreaves, 1991; Speck, 1998) by making a strategic shift towards endorsing teachers by being less rigid and being more approachable when interacting with teachers (Speck, 1998: 219). The importance of the school principal in creating a collective vision for the professional learning community (DuFour \& Eaker, 1998; Speck, 1998; Spence, 2009) and connecting the school expenditures to teacher development (Speck, 1998: 171-79) were important aspects uncovered in the literature.

\section{The Empirical Investigation}

The research method for the empirical investigation employed both quantitative and qualitative research approaches. With the quantitative research design of the mixed methods research approach a questionnaire was utilised that was sent to 200 respondents during the beginning of June 2010 and returned by the end of July 2010. From the 200 questionnaires distributed, 145 were returned representing a $73 \%$ return rate. The development of the questionnaire involved the alignment of the literature review with the formation of the questions to ensure the sound relevance of the instrument used to answer the initial research question regarding the 
development of a school-based model for teacher development as pursued by the research aims concerning the components of teacher development, the main elements of a professional learning community and the role of the school principal in teacher development. The piloting of the questionnaire determined the validity and reliability of the device. The self-administered questionnaire was distributed to teachers and school principals in a specific English Public school district and a university's teacher education faculty within a small Northern Ontario community of 54,000 people.

The questionnaire data indicated that teachers and school principals believe in the value of teacher development and that teacher development can improve teacher performance and thereby improve learner achievement. Ongoing professional development over a teacher's career span contributes to gradually improved teaching practise. Some teachers, however, do not feel obligated to continually develop as professionals after completing initial teacher training, because they feel they have completed the requisite long-established teacher preparation program. A fair percentage of respondents were unaware of whether provincial test scores had improved, declined, or were unchanged which was alarming because in order to maintain improved classroom practise for enhanced learner achievement, using data to make informed decisions regarding teacher development must be an essential component of school based teacher development. Teachers and school principals must use provincially gathered data on standardised test scores to have a measurement baseline for the determination of instructional techniques, resources, and methods of teacher development.

Respondents indicated at $92 \%$ that professional development should take place during the instructional day yet, school districts have not typically offered flexibility regarding the idea of teachers completing professional development during the instructional day. The correlation between staff development during instructional time which is free of charge is revealed in figure 1 .

Figure 1: Development during instructional time and development free of charge

\begin{tabular}{|c|c|c|}
\hline & & Development free of charge \\
\hline $\begin{array}{l}\text { Development } \\
\text { instructional time }\end{array}$ & Pearson Correlation & $.544 * *$ \\
\hline
\end{tabular}

It was determined that there exists a statistical correlation between the variables of professional development occurring during the instructional day and the appeal for professional development to be free of charge. In figure 1 this stronger correlation is revealed. Should continuous development occur during the instructional day this in turn will satisfy the school district when the employer is provided with the improved learner achievement statistics on account of improved teaching competence. The development of teachers when sponsored by the employer is more likely to be supported by teachers than when they have to pay for professional development out of their personal salary. Teachers' professional development sponsored by the school district must additionally be aligned with the instructional needs of the learners in the classroom. 
A strong relationship exists between teachers' years of work experience and qualifications obtained since teachers acquire more Additional Qualification (AQ) courses as they gain in years of experience. In addition, as teachers increase in more years of experience they would also engage with a greater number of school principals each school principal influencing teachers' professional development differently. Standardised testing data to improve learner achievement is central to teacher development and school improvement planning. In figure 2 a negative connection exists with regard to provincial test score data and the completion of Additional Qualification courses in that teachers who have completed less Additional Qualification courses have limited knowledge regarding the status of provincial test score data. The implication is that teachers who do not complete professional development activities likely do not use or know how to use learner achievement data to improve instruction.

Figure 2: Provincial test score data and Additional Qualification (AQ) courses completed

\begin{tabular}{|l|l|l|}
\hline & & $\begin{array}{l}\text { Additional Qualification } \\
\text { Courses }\end{array}$ \\
\hline Provincial Test Scores & Pearson Correlation & $-.175^{*}$ \\
\hline
\end{tabular}

Figure 3 identifies that beginning teachers require additional professional development than do experienced teachers and the more development obtained the more teachers appreciate the increased attainment of professional development for themselves as well as their beginning colleagues.

Figure 3: Education attained and the value placed on further professional development

\begin{tabular}{|l|l|l|}
\hline $\begin{array}{l}\text { New teachers more } \\
\text { development }\end{array}$ & Pearson Correlation & Education attained \\
\hline
\end{tabular}

In addition, figure 4 illustrates that the more professionally developed teachers place stronger value on workplace trust as the foundation for participatory decision making between school principals and teachers with school principals actively seeking input from teachers on school matters.

Figure 4: The necessity and importance of a culture of trust and education attained

\begin{tabular}{|l|l|l|}
\hline & & Education attained \\
\hline Culture of trust necessary & Pearson Correlation & $.263^{* *}$ \\
\hline
\end{tabular}

More professionally developed teachers also put a high priority on teacher development to take place during staff meetings which in general should be organised monthly in addition to monthly subject or division team meetings. Teachers should always attend these meetings which should last between thirty and sixty minutes and which should occur during the instructional day. As the basis of teacher development in order to improve teaching competencies data on standardised testing from the Education Quality and Accountability 
Office (EQAO) should function as the baseline point for school principals to improve learner achievement.

A culture of trust between the school principal and teachers facilitates school principals to consult teachers on school improvement which enables teachers to be active participants in their own development and in school improvement matters. Figure 5 highlights that a culture of trust is also paramount when considering the learner achievement data from the Education Quality and Accountability Office.

Figure 5: A culture of trust in considering the data from the Education Quality and Accountability Office (EQAO) to enhance learner achievement

\begin{tabular}{|l|l|l|}
\hline & & $\begin{array}{l}\text { EQAO data to enhance } \\
\text { achievement }\end{array}$ \\
\hline Culture of trust necessary & Pearson Correlation & $.449^{* *}$ \\
\hline
\end{tabular}

By utilising learner achievement data to improve teaching and learning, workplace trust empowers teachers and school principals to consider data within the context of improving teacher performance so as to increase learner achievement. Figure 6 identifies the utilisation of data from the Education Quality and Accountability Office at monthly staff development meetings assist teachers in using criterion-based learner provincial assessment scores to uncover specific focus areas in literacy and numeracy for improved classroom teaching.

Figure 6: Data from the Education Quality and Accountability Office (EQAO) to enhance school improvement via meetings

\begin{tabular}{|l|l|l|}
\hline & & $\begin{array}{l}\text { School improvement in } \\
\text { meetings }\end{array}$ \\
\hline $\begin{array}{l}\text { EQAO data to enhance } \\
\text { achievement }\end{array}$ & Pearson Correlation & $.628^{* *}$ \\
\hline
\end{tabular}

Within a professional learning community paradigm these classroom improvement approaches should also be discussed by the school principal and teachers by means of engaging in professional dialogue during breaks.

The three most popular methods of teacher development are peer coaching/mentoring, action research/reflective practise, and professional learning community meetings as shown in figure 7. 
Figure 7: Respondents' opinions on most effective professional development methods

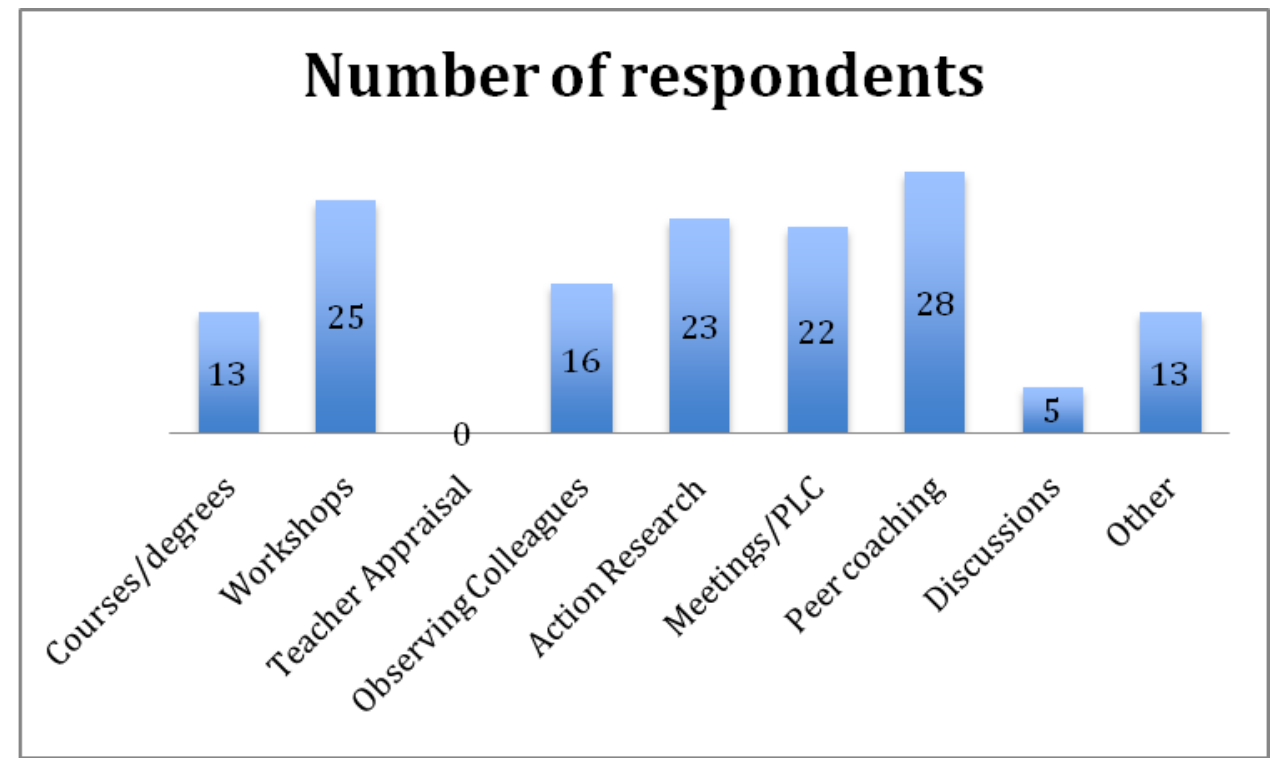

School principals can use these approaches individually or as a group effort. Peer coaching/mentoring as a teacher development approach entails teachers visiting and observing their colleagues' classrooms during the instructional day. Schools using the peer coaching approach with action research produce positive gains in learner achievement within a professional learning community paradigm.

The second portion in the mixed methods research approach involved the deeper probe to identify regularities regarding staff development via in-depth semi-structured individual interviewing. The pilot interviews initially completed confirmed the inclusion of all pertinent topics in an interview guide. The results of the qualitative data component yielded six themes that emerged via open coding. The six themes included: A relationship of trust between school principals and teachers, school principals communicating with teachers, the school principal as a facilitator of teacher development, the resources necessary for teacher development, leading methods of teacher development and using data to improve the instructional practise of teachers.

Participants were unanimous in that in order for teachers to develop as professionals a pre-existing relationship of trust between teachers and the school principal was identified in the quantitative and qualitative data. Participants agreed that punitive methods used by school principals towards teachers severely hampers teacher development. When school principals defend their teachers in conflict with learners and parents, teachers often interpret these actions as supportive and thus school principals earn the trust of the teachers. School principals improve teacher trust through the gradual release of managerial responsibility and by consulting with teachers when making school based decisions as was identified in the qualitative data. By seeking dialogue from teachers about school issues on a regular basis, school principals exhibit a behaviour pattern to teachers that is supportive and that is viewed as loyal regarding the daily instructional responsibilities of teachers. Acquiring the trust of 
teachers is the basis for effective teacher development efforts initiated by the school principal. School principals must begin a relationship of trust with teachers to create a workplace culture where teachers are not afraid to make mistakes or to pose questions so as to develop as professionals.

The second theme from the interviews was communication. Participants all agreed that communication matters. Communication is important for teacher development and professional discourse between the school principal and teachers during formal staff and professional learning community meetings and informally in the hallway or staffroom is paramount to improving instruction. An environment of professional communication enables school principals to convey their vision for the school to teachers in order to create a shared vision for the school. In this regard supplementing the daily workplace communication of school principals and teachers with informal social gatherings creates social cohesion and the spark of productive discourse around instructional practise. As formal school based meetings must be focussed in order to maximise time devoted to the conveying of the school's vision and mission statements into set goals and targets for the realising of school improvement and refined instructional strategies, items not connected to such discussions should be communicated. Teachers will have opportunities during the instructional day to read emails and newsletters depending on their personal work schedules. School principals as promoters of teacher development filter organisational material to their teachers to ensure teachers are exposed to important matters to be distributed and they act as mediators between the school district and the teachers. In relation to effective communication school principals should function as informational resources by providing teachers with informative articles to read, connecting teachers with the appropriate school district personnel who can transfer information on instructional techniques for the sake of improved teacher practice.

The third theme from the interviews was the school principal as a facilitator of teacher development. The qualitative interviews stressed that by leading by example, effective school principals participate in ongoing professional development themselves, which displays the value of continual development to teachers. Interviewees stated that when teachers feel good about professional development and the climate in the school, they are more inclined to be open about learning new methods of instruction through professional development opportunities. Effective school principals also facilitate teachers to intrinsically seek out professional development and they create professional development opportunities for teachers. In this regard school principals must be willing to take risks concerning curriculum leadership by being visible in classrooms and attempting instructional techniques and then asking teachers for feedback about their lessons to create a professional learning environment.-

The fourth theme identified in the interviews was the resources required for teacher development, which includes sufficient time, physical space and materials in order to improve instructional techniques. Within a professional learning community, school principals can allocate time during the instructional day for teachers to meet for professional development purposes. The hiring substitute teachers to cover classes while teachers are involved in 
professional development activities is not a productive option due to costs and creates additional work for teachers who have to plan and prepare for a substitute teacher to teach while regular classroom teachers attend meetings. Timetabling for teachers to meet for professional development should not place additional work on teachers to create lesson plans for classes which they will not be teaching.

Professional development meetings should not take place at the end of the instructional day due to conflicts with the after-school duties of teachers such as lesson planning, preparing for instruction, assessment, evaluation, reporting to parents, as well as extra-curricular activities. Properly providing time during the instructional day is therefore crucial to effective teacher development. Combining classes, using professional development days for school-based professional development instead of teachers attending centralised school district mass curriculum workshops, and organising guest speakers for learners to allow teachers time to engage in professional development.

Financial resources are essential to teacher development and school principals must match school expenditures with improving learner achievement by linking budgets to improving learner outcomes and the implementation of the vision of the school. The approaches most appropriate for teacher development must be aligned to learner achievement data in order to be effective and choices regarding teacher development cannot be decided solely on the interests of the teacher, but should be linked to areas for improvement based on learner achievement data. Peer coaching is a constructive approach to teacher development and school principals should facilitate opportunities for teachers to observe and learn from other teachers during the instructional day to share instructional techniques to improve learner achievement.

The fifth theme uncovered in the interviews focused on the methods of teacher development. Due to the ineffectiveness of the Teacher Performance Appraisal (TPA) system of instructional supervision for teacher development and with the lack of coaching relationships not built on mutual trust and respect informal self-created tutoring partnerships among teachers can be of significant value for teacher development. There does not exist one single method to teacher development and differentiating professional development to fit each individual teacher's specific requirements is important for teacher growth. Teacher development approaches such as action-research foster teachers' interest and ownership of professional development and maintain lasting teacher development when supported by a trusted coach or mentor within a professional learning community. Although curriculum based workshops are simply prepared and typically low-cost, they do not account for the needs of the individual teacher or for sustaining teacher development with continual maintenance. Teacher development must initially be intrinsically motivated by teachers themselves to pursue workshops, additional courses, and appropriate coaching and action research methods to improve their instructional practise. When teachers are not self-motivated, school principal must play a more important role in motivating teachers to develop professionally. 
The sixth theme from the qualitative data related to the utilisation of learner assessment to enhance the instructional practise of teachers through the Education Quality and Accountability Office (EQAO) of Ontario and the usage of standardised testing data is a contemporary approach to teacher development. Sufficiency is created when teachers at the beginning of each new school year have discussions with teachers who taught the classes the previous year to identify what the instructional focus areas should be with the incoming class based on past learner achievement data.

The Teaching-Learning Critical Pathway (TLCP) professional learning community model implemented in Ontario to improve learner achievement in literacy and numeracy facilitates teachers working together to examine learner achievement data and identify a common focus areas and methods to focus on across all classrooms. The TLCP model enables dialogue regarding enhancing learner achievement by way of improving teacher development which is dealt with in formalised TLCP meetings that take place once a month. With regard to teachers' professional development school principals should utilise multiple forms of data to consider for the enhancement of teacher instruction for the sake of learner achievement in a professional learning community environment. Data such as standardised testing data, report card data, learner attendance and suspension data, teacher absenteeism data, and pre-test/post-test Teaching-Learning Critical Pathway (TLCP) data are all examples of useful data to be considered in teacher development efforts for the sake of school improvement. To ensure that teacher development is effective, a trusting relationship between school principals and teachers is paramount, which is sustained through effective communication by means of which school principals and teachers utilizing data to enhance teacher performance and thereby improve learner achievement ensuring lasting and sustained teacher development for sustained school improvement.

\section{Conclusions}

Flowing from this summary and with reference to the study's research questions and research aims, conclusions are drawn which include the following:

- A clear vision should be communicated by school principals to teachers to formulate a shared mission and to develop a healthy school culture focused on staff's professional development for the sake of improved learner achievement.

- Comprehension of provincial data which consists of learners' achievements in standardised testing is a key component to identify areas for improvement in the instructional practise of teachers. Teacher development in order to have an understanding of the outcomes from provincial test results is therefore a crucial component of a teacher professional development programme.

- Standardised learner assessment data facilitates the classification of areas for teacher development in literacy and numeracy and the identification of a baseline starting point to measure the success of teacher development activities. This data appear in different forms such as standardised provincial test scores, report card school profile data, 


\section{Mll Macrothink}

attendance records of learners and teachers, learner suspension and expulsion rates and school generated data from Teaching-Learning Critical Pathway (TLCP) activities.

- This data should be shared and analysed by the school principal and teachers to identify the needs of learners and gaps in the instructional techniques of teachers for further development.

- Professional development is valued more by teachers who have attained higher levels of teacher development and teacher development initiatives are especially important to enhance the competencies of novice teachers.

- A culture of trust is necessary in the workplace for teacher development to occur and teachers who have obtained a significant number of additional qualifications do especially value this culture of trust in the workplace. A culture of trust is developed by discussing standardised test data at meetings where teachers and school principals mutually identify focus areas for establishing goals to improve teacher instruction and learner achievement which then articulate into school improvement.

- Teacher development approaches which include Teacher Performance Appraisal (TPA) do not produce effective professional development opportunities.

- School principals establish trust with teachers using a respectful delicate approach through consultation to obtain teacher input, using task and people accommodations when teachers require improvement in instructional techniques, supporting staff when interacting with parents, not favouring some staff over others and possessing convincing technical skills and work ethics.

- For the sake of successful staff development school principals should effectively filter directives for teachers from the school district and Ministry of Education.

- School improvement planning for the sake of enhanced learner achievement should be the main focus of all staff meetings and is especially valued by better qualified teachers.

- Professional development for teachers should occur during the instructional day due to the occupational demands on teachers after the end of the normal school day and should be in the form of staff meetings and subject or division team meetings held on a monthly basis and attended by all teachers. These meetings should last between thirty and sixty minutes in length whereby school principals mediate teacher development during these meetings.

- Meeting time must be spent on matters relating to improving teaching and learning. Other matters for notification should be distributed to teachers via email, journal articles and newsletters and memos in staff mailboxes.

- Organising the instructional day to facilitate the professional development of teachers can occur through the timetabling of schedules, releasing teachers by in-school 
coverage such as organising guest speakers for learners to attend, and combining classes.

- Professional development must not be a financial cost to the individual teacher and any costs associated must be sponsored by the employer.

- A professional learning community approach is significant to improving the instructional techniques of teachers and teachers are more responsive to teacher development activities when these activities are focused on learner achievement data and school improvement planning.

- The ability of school principals to communicate is a central factor in the accomplishment of school-based teacher development and school principals should therefore be able to engage teachers in conversations of a professional nature at every opportunity, such as informal encounters at gatherings and conversations in the hallway and staffroom in addition to formal staff meetings. School principals should visit classrooms regularly and discuss learner achievement with teachers.

- The three approaches most conducive to teacher development are peer coaching/mentoring, action research/reflective practise and professional learning community meetings. School principals can utilise these methods individually or as part of a larger approach within the school's comprehensive teacher development plan. A combination of a peer coaching and action research approach within a professional learning community arrangement is functional to enhance and sustain learner achievement.

- School principals are the facilitators of teacher development and the ability of the school principal to motivate teachers to improve their instructional techniques is paramount within a professional learning community environment. School principals should therefore facilitate teacher development by leading through example and by scheduling and creating opportunities for teachers to pursue professional development activities. Important characteristics required of school principals to facilitate teacher development include being organised, honest and direct and being prepared to take risks and support and partake in courageous conversations with teachers with regard to their personal professional development plans.

\section{Recommendations}

The following recommendations are made:

- The school principal should initiate the process of teacher development beginning with the timetabling of classes to ensure that teachers are released during the normal instructional day through internal (substitute) coverage of classes. In connection with the implementation of release time, teachers will require physical space to meet. School budget expenditures on items such as classroom supplies, field trips, and other expenses should be linked to improving learner achievement through teacher development. Teachers should not incur any personal costs associated with teacher 
development activities. School principals should manage these tasks while preforming traditional roles such as dealing with learner discipline.

- A school based professional learning community is built on a trusting relationship with school leadership. The leadership role of the school principal is augmented through high standards of managerial skills and modelling/filtering directives from the school district and Ministry of Education. School principals should use a delicate approach such as supporting and encouraging individuals when teachers may have lagging instructional skills in some areas and require improvement. School principals should also request teacher involvement in school decision making to foster a participatory decision making process in the school in order to arrive at more informed decision-taking while simultaneously providing opportunities for teacher development.

- Teacher development requires a school principal who is an effective communicator. Effective school principals should have a clear vision for the school and be able to communicate with teachers a shared vision and mission statement for the school. School principals should therefore engage teachers in discussions regarding staff development for the improvement of learner achievement at formal meetings and at informal opportunities to connect with teachers in courageous conversations. Communication requires principals to be visible in the school by visiting classrooms and talking with teachers and learners.

- The interpretation and consideration of data whether data on standardised test scores, report card/school profile data, suspension/expulsion records, attendance of learners and teachers, and other school generated learner assessment data is compulsory. Data advances the identification of areas for teacher development by establishing a baseline and starting point from which schools can measure the success of teacher development activities.

- Once areas for improvement in learner achievement have been identified, teacher development to improve gaps in instructional practise can commence. School principals will have greater success in improving teacher performance when they have created the foundation for teacher development through managerial and leadership actions initiated. Teacher development requirements should be tailored to the individual teacher in the form of peer coaching (mentoring) and action research (reflective practise) within the established professional learning community. These activities will require time for individual teachers and small groups of teachers to meet as timetabled to be part of the formal school day.

- The school principal facilitates the teacher development process by enabling teachers to meet during the instructional school day due to teacher workload constraints and limits placed on meetings after school by Teachers' Unions. Teacher development activities should be based on the evidence from data to evaluate the achievement of peer coaching and action research. 
- The functioning and progress of teacher development will originate during monthly staff, subject/division and school improvement planning meetings within a professional learning community framework. Each meeting should take place during the normal instructional school day and should last between thirty to sixty minutes.

Figure 8 indicates the scope of conditions needed for the school based teacher development model to function effectively.

\section{Figure 8: A model for school based teacher development}

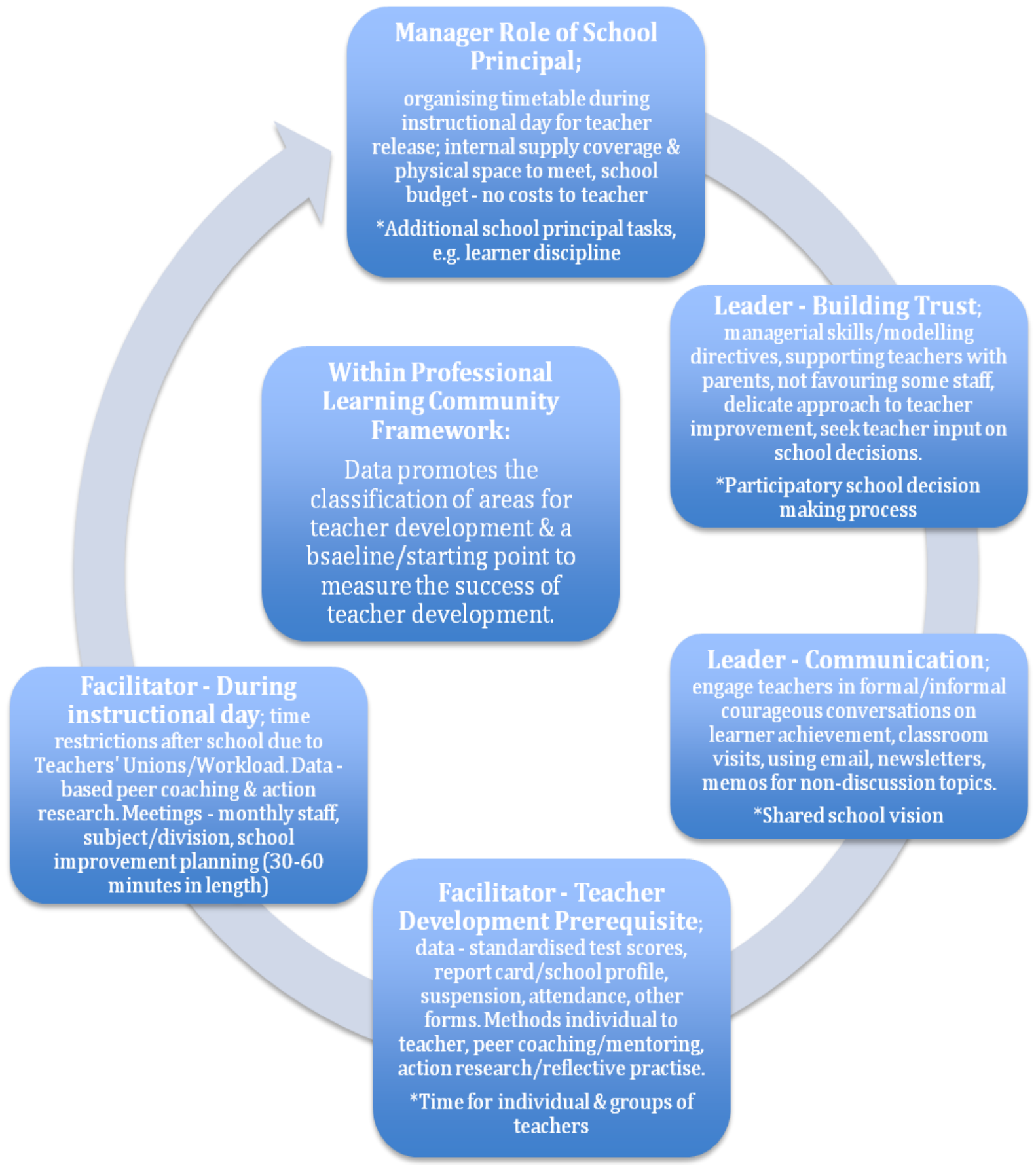




\section{Mll Macrothink}

This model for teacher development depicted in figure 8 is a long-range plan. The school principal can initiate the teacher development process before the school year begins by making teacher development a priority through a focus on creating a daily schedule that will allocate time for teachers to come together during the normal instructional day for a minimum of one hour per week. When school budgets and expenses are being determined, the school principal should decide to focus on items that have a correlation to staff development for the sake of improved learner achievement. On the days when staff development meetings are taking place, school principals should not schedule meetings with parents or other stakeholders so as to be in a position to attend the school based staff development meetings exclusive of their other obligations. At these meetings teachers should contribute to the decision making processes regarding the improvement of learner achievement, such as the creation of a shared school vision for the determining of objectives to be realised. School principals should remember that any effective relationship is built on trust and be sure to equally back all teachers regarding demands with parents and to be tactful when teachers require improvement.

School principals should plan to spend a couple of hours daily engaging in communication with teachers regarding improved teaching for the sake of improved learner achievement. Courageous conversations can take place in school based meetings or informally during classroom walkthroughs or instructional rounds to observe the teaching taking place in classrooms. When visiting classrooms the motivation for these visits is not to be an inspector, rather it is to discuss learner achievement with both learners and teachers. At every opportunity the school principal should clearly communicate the shared school vision. Matters of notice that do not require intense teacher consultation should be conveyed to staff via email and newsletters and not be discussed at meetings that are focused on staff development for the sake of learner achievement.

At meetings during the instructional day, teachers and the school principal can appraise the existing forms of learner achievement data, such as standardised test scores, report card/school profile data, learner attendance and disciplinary data, teacher absenteeism data, and other school generated learner achievement data to establish a baseline from which teachers can measure improvements in learners and thereby gauge their own instructional practise. Once the areas of focus are established, the school principal can facilitate the teacher development process by ensuring that teachers are provided with the financial resources necessary, connecting teachers requiring support with a peer coach, a senior teachers or school district staff with specific expertise to mentor the teacher. The teacher and peer coach/mentor can begin an action research project using the existing data to improve the instructional techniques of the teacher. During meetings, teachers can exchange ideas and strategies centered on learner achievement based on the professional learning community paradigm.

The cyclical process of gathering data throughout the year will enable teachers and school principals to formatively assess the progress being made and make any necessary adjustments in the teacher development procedure. Gathering data throughout the year-long school cycle is essential to improving teacher instruction and learner achievement. When schools only employ 
year-end data to make decisions, the results cannot be applied and changes cannot occur until the following school year.

\section{Suggestions for further study}

This research has accomplished its goal to develop a school based model for optimising the professional development of Canadian primary school teachers. With reference to the recommendations for this research regarding the development of a school based teacher development model for Canadian primary school teachers the following are suggested for future study:

- This study was focused on primary schools within a Canadian context. It would be advantageous to extend this research to secondary schools to verify if different results might be found regarding the creation of a teacher development model for secondary school teachers.

- Research should also be performed to assess whether school funding models should be calculated based on the needs of the learners and support required for teacher development rather than the existing school dimension/learner enrollment method currently used in a Canadian context.

It would also be valuable to determine the role of parents and guardians in learner achievement as part of the school improvement planning process. It would therefore be worthwhile to go beyond teacher and school principal perspectives in order to examine the parental involvement role in improving learner achievement. To undertake such an investigation the focus should be on:

- How do parents perceive their role in learner achievement?

- What are the similarities and differences between how school staff and parents view their role in improving learner achievement?

- What role should parents play within mainstream schools to foster learner achievement?

- What are the realistic goals that may be achieved by schools regarding parental involvement given the current governmental policies regarding the role of parents in curriculum and schools?

- What existing features of school-to-parents communication and involvement can be extracted and utilised in the school improvement planning process?

- How has the role of parental involvement in learner achievement changed in the contemporary school climate?

- What are the general guidelines and practical ways in which parents can contribute to the school climate to facilitate learner achievement?

- How can the role that community resources and agencies play within the school in enhancing learner achievement be improved? 


\section{Limitations of the study}

This study was limited in the fact that it focused heavily on the role of the school principal in the teacher development process. The recommended teacher development approach relies on a strong school principal in order to improve learner achievement. In addition, this study was limited by concentrating on a community in the northern part of the province of Ontario, Canada which had a small quantitative sample size of 200 respondents.

\section{Concluding remarks}

The findings of this study contributed to the existing pool of knowledge on teacher development within the context of a professional learning community environment. The interactive strategy/model that was developed for school principals to consider in the professional development of teachers contributed to the understanding that the existing problems associated with learner achievement are symptomatic of the larger problem of inadequate teacher development. Moreover, this research encouraged school principals to shift from the traditional thought-process of teacher development to the more interactive model of teacher empowerment.

The importance of creating a professional learning community within the school is of value since it identifies elements that should be considered when preparing future school principals for the demands of school management. In that regard the study contributed to an understanding of the formal and informal interactive professionalism that is occurring in schools as it applies to the change process and potential opportunities for school improvement planning. The study outlined the factors shaping the encompassing teacher development actions occurring in school communities. Just as educators require training to be effective in their arduous role as classroom teachers, so do school principals need additional preparation to maintain equilibrium in opposition to the onerous accountability forces shaping schools. School principals constantly need assistance to sensitise them to the daily opportunities for teacher development in the school.

\section{References}

BARTH, R. 2001. Learning by heart. San Francisco: Jossey-Bass.

BLANKSTEIN, A. 2004. Failure is not an option: Six principles that guide student achievement in high-performing schools. Thousand Oaks, CA: Corwin Press.

BLASE, J., \& BLASE, J. 1998. Handbook of Instructional Leadership. California: Corwin Press.

CALHOUN, E. 1994. How to use action research in the self-renewing school. Alexandria, VA: Association for supervision and curriculum development.

DARLING-HAMMOND, L. 1993. Reframing the school reform agenda: Developing capacity for school transformation. Phi Delta Kappan, 74(10), 752-61. 
DARLING-HAMMOND, L., \& BRANSFORD, J. 2005. Preparing teachers for a changing world. San Francisco: Jossey-Bass.

DAY, C. 1999. Developing teachers: The challenges of lifelong learning. Philadelphia: Falmer Press.

DELONG, J., BLACK, C., \& WIDEMAN, R. 2005. Action research for teaching excellence. Ontario: Data-Based Directions.

DUFOUR, R. 2007. Professional learning communities: A bandwagon, an idea worth considering, or our best hope for high levels of learning. Middle school Journal, 39(1), 4-8.

DUFOUR, R., \& EAKER, R. 1998. Professional learning communities at work: Best practices for enhancing student achievement. Bloomington, IN: National Education Service.

FROST, D., DURRANT, J., HEAD, M., \& HOLDEN, G. 2000. Teacher-led school improvement. New York: Taylor \& Francis.

FULLAN, M. 2001. What's worth fighting for in the principalship. New York: Teachers College Press.

FULLAN, M., HILL, P., \& CREVOLA, C. 2006. Breakthrough. Thousand Oaks, CA: Corwin Press, Inc.

HANNAY, L., WIDEMAN, R., \& SELLER, W. 2006. Professional learning to reshape teaching. Toronto: Elementary Teachers' Federation of Ontario.

HARGREAVES, A. 1991. Contrived collegiality: The micro-politics of teacher collaboration. In J. Blaise (Ed.), The politics of life in schools (pp. 46-72). New York: Sage.

HARGREAVES, A. 1994. Changing teachers, changing times: Teachers' work and culture in the postmodern age. New York: Teachers College Press.

JOYCE, B., \& SHOWERS, B. 1995. Student achievement through staff development. New York: Longman.

LACEY, C. 1977. The socialization of teachers. London: Methuen.

LEITHWOOD, K. 1990. The principal's role in teacher development, in Joyce, B. (ed.) Changing school through staff development. Alexandria: Association for supervision and curriculum development. 
MCNERGNEY, R., \& CARRIER, C. 1981. Teacher Development. New York: Macmillan Publishing.

MEIER, D. 1995. The power of their ideas. Boston: Beacon.

O’DAY, J. 2002. Complexity, accountability, and school improvement. Harvard Educational Review, 72, 293-329.

Ontario Ministry of Education. School Board Profiles. (Online). Available at: <http://esip.edu.gov.on.ca/english/> Accessed: 15/03/2009.

PARKAY, F., STANFORD, B., VAILLANCOURT, J., STEPHENS, H. 2005. Becoming a teacher. Toronto: Pearson.

PITT, J. 2011. Informal School Based Teacher Development. International Review of Social Sciences and Humanities, 1(2), 26-39.

PITT, J., \& KIRKWOOD, K. 2009. Destructive staffroom discourse. Journal of Unschooling and Alternative Learning, 3(5), 16-30.

SPECK, M. 1998. The principalship building a learning community. New Jersey: Prentice hall.

SPENCE, C. 2009. Leading with passion and purpose: creating schools that help teachers teach and students learn. Ontario: Pembroke.

THIES-SPRINTHALL, L. 1984. Promoting the development growth of supervising teachers: Theory, research programs, and implications. Journal of Teacher Education, 35(3), 53-60.

THIES-SPRINTHALL, L., \& REIMAN, A. 1994. Curriculum for developmental instructional supervision. USA: North Carolina State University. 